\title{
Application of gold nanoparticles for improvement of analytical characteristics of conductometric enzyme biosensors
}

\author{
O. O. Soldatkin ${ }^{1,4} \cdot$ O. V. Soldatkina ${ }^{2,3} \cdot$ I. I. Piliponskiy ${ }^{1} \cdot$ L. S. Rieznichenko ${ }^{2} \cdot$ T. G. Gruzina ${ }^{2} \cdot$ S. M. Dybkova ${ }^{2}$. \\ S. V. Dzyadevych ${ }^{1,3} \cdot$ A. P. Soldatkin ${ }^{1,3}$
}

Received: 29 December 2020 / Accepted: 15 March 2021 / Published online: 8 May 2021

(c) The Author(s) 2021, corrected publication 2021

\begin{abstract}
In the work, the possibility of using nanoparticles of gold (AuNPs) to upgrade bioselective elements of biosensors in order to improve their analytical characteristics is considered. The bioselective elements of biosensors based on acetylcholinesterase (AChE), butyryl cholinesterase (BuChE) and glucose oxidase (GOD) were used as an experimental model. Immobilization of enzymes on the surfaces of conductometric transducers was performed by the crosslinking of corresponding enzymes using glutaraldehyde. The conditions of immobilization of AChE with gold nanoparticles were optimized. Thus, we determined the optimal values of concentration of crosslinking agent (glutaraldehyde), duration of immobilization, the enzyme to AuNPs ratio, the AuNPs concentration and size. The performance characteristics of the biosensors based on enzymes and AuNPs were investigated and compared with the characteristics of biosensors based on enzymes only. It was also examined how the addition of AuNPs to the bioselective element of biosensors affects the biosensor stability. In particular, the reproducibility of preparation and continuous operation of biosensors was tested as well as their stability at storage. It was shown that the presence of AuNPs in the composition of bioselective elements can improve some characteristics of biosensors, which may be promising for further study and use.
\end{abstract}

Keywords Biosensor $\cdot$ Conductometry $\cdot$ Enzyme $\cdot$ Gold nanoparticles $\cdot$ Acetylcholinesterase $\cdot$ Butyrylcholinesterase $\cdot$ Glucose oxidase $\cdot$ Bioselective elements

\section{Introduction}

The development of new methods for diagnosing diseases of humans and farm animals is an extremely urgent task of biotechnology. A promising approach is the use of biosensors, new analytical devices combining the achievements in biology, physics, chemistry, mathematics, microelectronics, etc. One of the options to improve the analytical characteristics

O. V. Soldatkina

olgasoldatkina@yahoo.com

1 Institute of Molecular Biology and Genetics of NAS of Ukraine. Zabolotnogo Str, 150, Kyiv 03143, Ukraine

2 F.D. Ovcharenko Institute of Biocolloidal Chemistry, NAS of Ukraine, Vernadskogo Ave, 42, Kyiv 03142, Ukraine

3 Taras Shevchenko National University of Kyiv, Volodymyrska Street, 64/13., Kyiv 01601, Ukraine

4 National Technical University of Ukraine "Igor Sikorsky Kyiv Polytechnic Institute”, Prosp.Peremohy, 37, Kyiv 03056, Ukraine of biosensors is the application of nanomaterials. Recently, biocompatible nanomaterials based on noble metals, polymers, and carbon are increasingly included in biosensors composition. At that, different nanostructures are used to improve various parameters of biosensor operation-efficiency, stability, sensitivity, and selectivity of detection.

Gold nanoparticles (AuNPs) can be widely used in enzyme-based biosensors. AuNPs are highly conductive and biocompatible, they are able to form strong thiol bonds with organic substances (eg, cysteine residues of enzymes) (Kerman et al. 2008). Thus, nanoparticles form a suitable microenvironment for enzyme immobilization. Also, the activity of the immobilized enzyme can be preserved by immobilization onto AuNPs (Hondred et al. 2017).

At present, it is already known about the development of a number of biosensors using AuNPs (Yang et al. 2020; Jia et al. 2020). For example, researchers have developed a biosensor for the analysis of formanate (organophosphorus pesticide). They used the enzyme laccase immobilized on a gold electrode, which was previously modified by electrochemically 
applied AuNPs (Ribeiro et al. 2014). The analysis was based on the inhibition of lactase activity by the pesticide. The biosensor has been successfully used to detect formanate in fruits. Another conductometric biosensor aimed at the hydrogen peroxide determination was based on horseradish peroxidase immobilized in a chitosan film with AuNPs (diameter $10 \mathrm{~nm}$ ) (Valencia et al. 2014).

Interestingly, the addition of nanoparticles resulted in a decrease of the biosensor sensitivity, which was explained by the authors as a result of the difference in the oxidative states of AuNPs and the horseradish peroxidase active center. The potentiometric biosensor for the determination of pesticide glyphosate is also known (Vaghela et al. 2018). The biosensor was based on urease immobilized with AuNPs (2.54 nm in diameter). Glyphosate inhibited urease, that was detected by a decrease in the signal of the ammonium-sensitive electrode. The biosensor developed to determine the activity of protein kinase A was based on horseradish peroxidase, antibodies (IgG), and AuNPs (Zhou et al. 2017). The use of nanoparticles made it possible to reduce the working potential to $0.08 \mathrm{~V}$.

The change in the diameter of AuNPs due to their aggregation, namely, an increase in the size during synthesis, leads to changes in optical properties of their suspension (the adsorption of light changes, which is accompanied by changing color). This phenomenon was used to develop a biosensor for colorimetric determination of acetylcholinesterase inhibitors (Pavlov et al. 2005). In the absence of inhibitors, the enzyme catalyzed the cleavage of acetylthiocholine to acetic acid and thiocholine. Thiocholine decreased the concentration of $\mathrm{AuCl}_{4}{ }^{-}$, which led to an increase in the diameter of AuNPs and to a change in the suspension color from pale pink to violet. In the presence of acetylcholinesterase inhibitors, neither AuNPs growth nor a corresponding change in the color of the solution was observed in the sample.

Given the positive effect of the presence of AuNPs on the analytical characteristics of biosensors, the aim of the work was formulated as follows: Study on the influence of gold particles, $30 \mathrm{~nm}$ and $20 \mathrm{~nm}$ in size, on the working analytical characteristics of AChE-, BuChE- and GODbased conductometric biosensors. Comprehensive studies on the development and modification of bioselective elements of biosensors with gold nanoparticles will give an answer whether this technology can influence the analytical characteristics of enzyme biosensors for the determination of important metabolites.

\section{Methods}

\section{Materials}

The reagents used in the work were as follows: glucose oxidase (GOD, EC 1.1.3.4) from Aspergillus niger with activity
272 U/mg (Genzyme, UK); acetylcholinesterase (AChE) from electric eel (EC 3.1.1.7) with an activity of $426 \mathrm{U} / \mathrm{mg}$, butyrylcholinesterase (BuChE) from horse blood serum (EC 3.1.1.8.) with an activity of $13 \mathrm{U} / \mathrm{mg}$, bovine serum albumin (fraction V), 50\% aqueous solution of glutaraldehyde (GA), butyrylcholine chloride, acetylcholine chloride, (SigmaAldrich Chemie, Germany).

Gold nanoparticles were synthesized according to the Turkevich-Frans method (Frens 1973; Turkevich et al. 1951) in their own modification by reduction of golden hydrochloric acid ( $\geq 99.9 \%$ trace metals basis, Sigma-Aldrich) with sodium citrate in the presence of potassium carbonate.

The compounds for buffers preparation and other inorganic compounds used in the work were of domestic production and were of the analytical grade of purity.

\section{Characterization of gold nanoparticles}

The morphology of the synthesized gold nanoparticles was determined by transmission electron microscopy (JEM-1400 (Jeol, Japan), Centre of collective usage NAS of Ukraine at D.K. Zabolotny Institute of Microbiology and Virology of the NASU) and laser-correlation spectrometer (Zetasizer-3, "Malvern Instruments Ltd"). According to the obtained data, the nanoparticles had a spherical shape and an average size of 20 and $30 \mathrm{~nm}$, respectively (Fig. 1).

\section{Coimmobilization of enzymes with gold nanoparticles using glutaraldehyde solution}

For the preparation of bioselective elements of biosensors by co-immobilization of gold nanoparticles and enzymes, we used the method of immobilization in a GA solution (by covalent immobilization of enzymes and auxiliary substances on the surface of the conductometric transducer). The basic enzyme solution contained 5\% (hereinafter-mass fraction) of acetylcholinesterase (or 10\% of butyrylcholinesterase or glucose oxidase), $5 \%$ of BSA in $100 \mathrm{mM}$ phosphate buffer, pH 7.0.

To form bioselective elements using nanomaterials, a colloidal solution of gold nanoparticles $(20 \mathrm{~nm}$ and $30 \mathrm{~nm}$ in diameter) (concentration $38.6 \mu \mathrm{g} / \mathrm{ml}$ ) was mixed with the enzyme solutions in various ratios, namely $5: 1,3: 1,2: 1,1: 1$, $1: 2,1: 3,1: 5$. The resulting nanoparticles-enzyme mixture was mixed with the aqueous GA solution $(0.2-1 \%)$ in ratio $1: 1$.

Before deposition of enzyme membranes, the sensitive areas of the conductometric transducer were treated with alcohol using a cotton swab. Next, they were washed with distilled water, and again wiped dry with a cotton swab. Immediately after that, the enzyme-gold nanoparticles-GA mixture was deposited on the transducers' working surfaces and dried for $40 \mathrm{~min}$ in the air at room temperature. The 

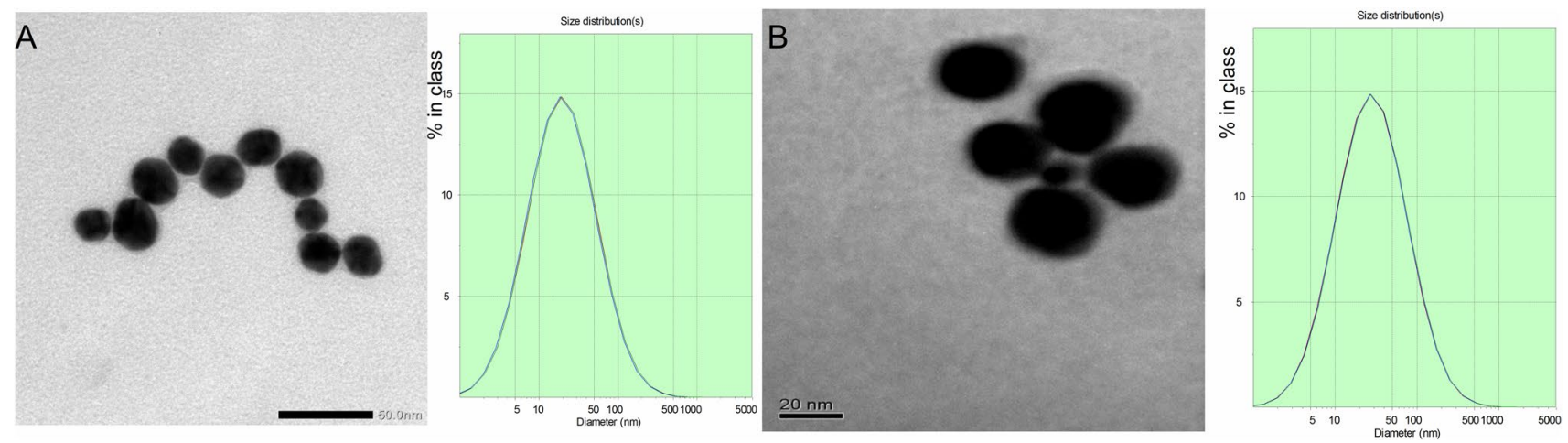

Fig. 1 Electron microscopic images and hydrodynamic diameter distribution of $20 \mathrm{~nm}$ (A) and $30 \mathrm{~nm}$ (B) AuNPs

membranes were deposited using an Eppendorf sampler $(0.1-2.5 \mu \mathrm{l})$. The approximate volume of the mixture to be deposited on the transducer surface for formation of a single membrane is $0.1 \mu \mathrm{l}$.

For the formation of reference membranes all procedures were carried out in the same way as for the working enzyme membranes, except that BSA of the same concentrations was added to the solutions instead of the enzymes. After immobilization, the biosensors were washed in a working buffer solution to remove unbound components of the biomembrane and excess glutaraldehyde.

\section{Conductometric transducers}

When creating conductometric transducers, noble metals are used as a material of the electrode, and non-conductive materials, namely glass or ceramics, are utilized for the substrate. The substrate material generally does not affect the sensitivity of the conductometric transducer. Most often, conductometric electrodes are prepared by photolithography method after thermal vacuum deposition of a gold layer on a sitall substrate (Dzyadevych 2005).

This approach was used in our work to create conductometric transducers. They were manufactured at the V.Ye. Lashkarev Institute of Semiconductor Physics (Kyiv, Ukraine) according to our recommendations. The conductometric transducers were $5 \times 30 \mathrm{~mm}$ in size and consisted of two identical gold interdigitated electrodes (Fig. 2). Each system had 20 pairs of raster electrodes with the bands/gaps dimensions of $20 \mu \mathrm{m}$ and a total sensitive surface area of about $2 \mathrm{~mm}^{2}$.

\section{Scheme of experimental device based on portable analyzer "MCP-3" for conductometric measurements}

Figure 3 presents a diagram of an experimental conductometric device for measurements using biosensors; on the left, the biosensor's schematic view is shown. An enzyme-based working membrane (3) was deposited on one pair of electrodes (1). The BSA-based reference membrane (4) was deposited on the second pair of electrodes (2). The portable conductometer MCP-3 (5) was developed and manufactured at the Institute of Electrodynamics of the National Academy of Sciences of Ukraine. The conductometric circuit includes a holder for biosensor 6 and a stand 7 . To carry out the measurements, the working cell 8 with the test solution 9 is placed on the stand base, the whole sensor block-on a magnetic stirrer 10 . The portable measuring device MCP-3 is connected to the network via adapter 11, to the biosensor-via the contact wires 12 , to the personal computer 13 with the installed software package-via contact 14 . The measurements were performed at a current frequency $37 \mathrm{kHz}$ and an amplitude $14 \mathrm{mV}$.

\section{Procedures of measurement}

The biosensor was placed in the $2 \mathrm{ml}$ working cell filled with buffer solution. After obtaining a stable initial signal (baseline), a certain aliquot of the initial solution of the substrate was added to the cell. The substrate concentration was changed by adding appropriate portions of stock solutions of substrates to the working buffer.

All studies using different techniques were performed at least 3 times. Because of using differential measurement mode, there were no non-specific changes in the output 


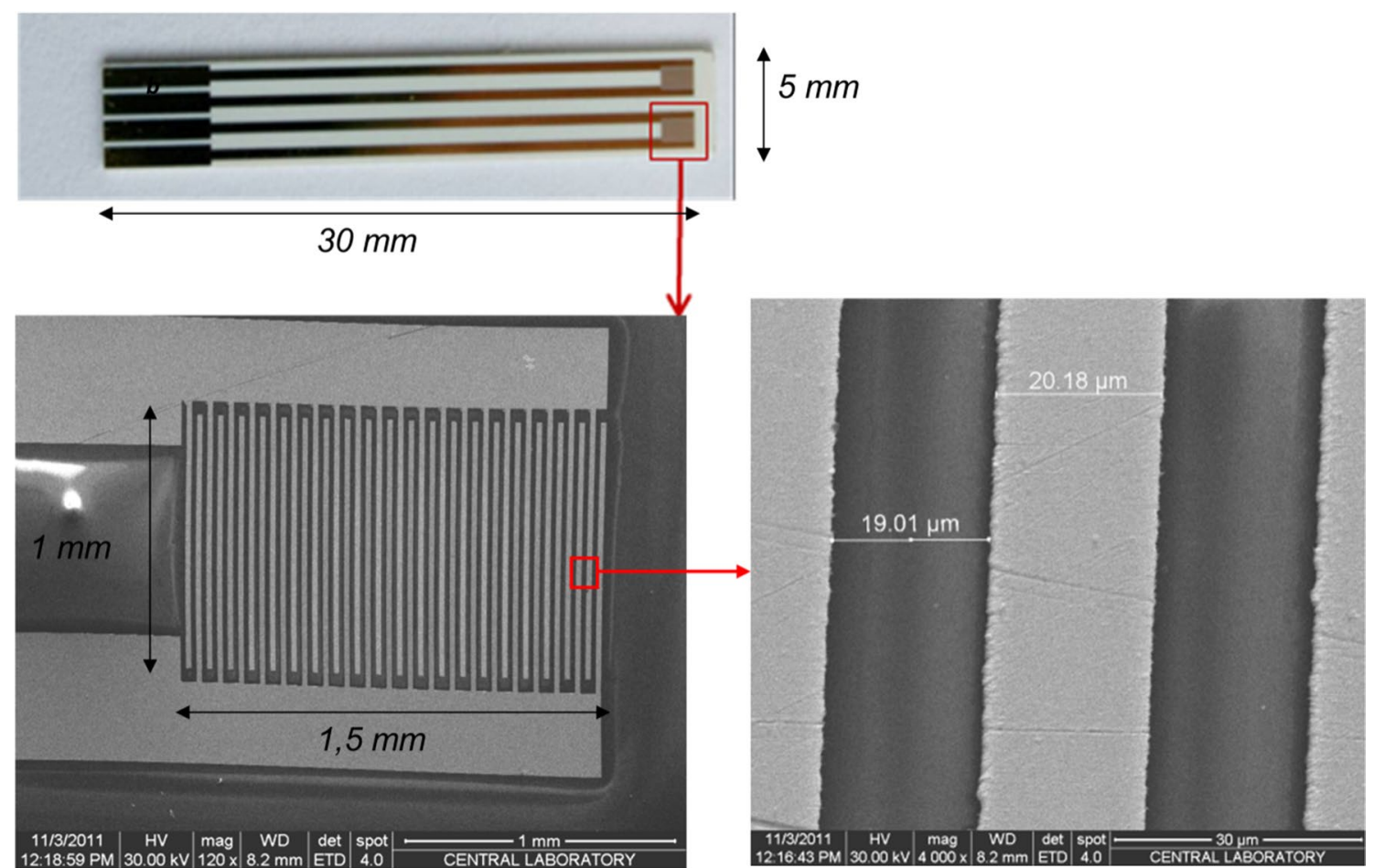

Fig. 2 General view of conductometric transducers with a differential pair of gold interdigitated electrodes deposited on a sitall substrate

Fig. 3 Scheme of conductometric device based on portable analyzer MCP-3

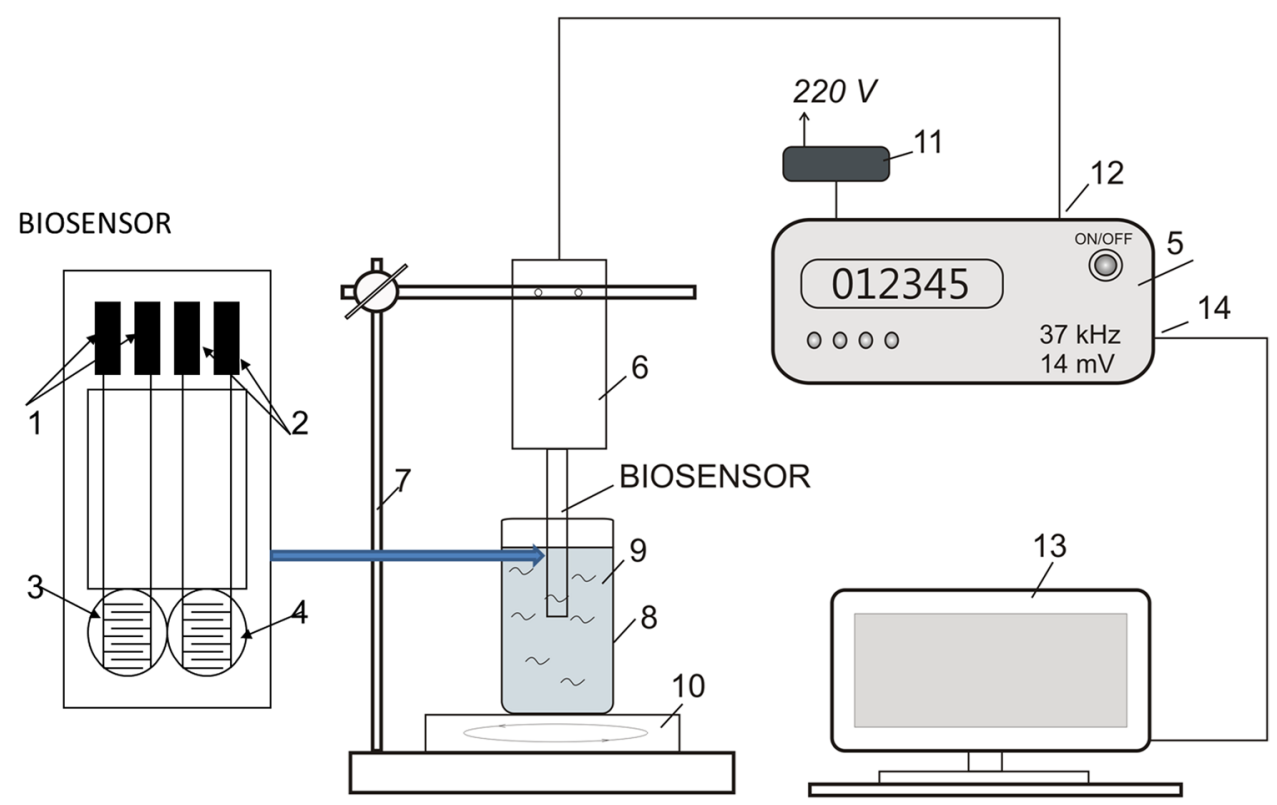

signal associated with the changes in temperature, medium $\mathrm{pH}$, electrical interference.

The results are given as the root-mean-square value \pm squared error of the mean value of the results of $\mathrm{n}$ independent experiments. The difference between the two groups was assessed using the Student's t-test, the difference was considered statistically significant when $p \leq 0.05$. 


\section{Results and discussion}

To study the effect of adding gold nanoparticles to the bioselective element on the functioning of biosensor, it is necessary to check its main analytical characteristics in case of the traditional procedure of enzyme immobilization and when using nanoparticles.

At the first stage of this work, it was necessary to optimize the conditions of immobilization of AChE with nanoparticles that will allow consequent comparison of the analytical characteristics of the obtained biosensor with those of the biosensor based on the traditional method of immobilization.

The enzymatic reaction underlying the operation of an AChE-based biosensor is:

$$
\text { Acetylcholine }+\mathrm{H}_{2} \mathrm{O} \rightarrow \stackrel{\mathrm{AChE}}{\text { Choline }+\mathrm{CH}_{3} \mathrm{COO}^{-}+\mathrm{H}^{+}}
$$

In the course of the enzymatic reaction (1) acetylcholine under the catalytic action of acetylcholinesterase is cleaved into choline and acetic acid. Acetic acid dissociates into an acid residue and a proton, the local concentration of ions in the working membrane increases, which, accordingly, leads to a change in the conductivity of the solution in the nearelectrode region, registered by a conductometric transducer (Jaffrezic-Renault \& Dzyadevych 2008; Soldatkin et al. 2008).

In this work, the immobilization of $\mathrm{AChE}$ with gold nanoparticles on the surface of conductometric transducers was performed in a solution of glutaraldehyde; the latter formed covalent bonds between the enzyme and auxiliary substance (BSA); during this process, the enzyme activity changed, depending on the GA concentration and the duration of immobilization.

To select the optimal GA concentration, the bioselective elements with the mass fraction of GA from $0.2 \%$ to $1 \%$ were produced. The responses to the substrate $(100 \mu \mathrm{M}$ acetylcholine) were very small at the GA concentration of $1 \%$. This is due to the fact that the residual activity of the enzyme was low after its immobilization in the presence of GA in a high concentration.

However, at low GA concentration $(0.2 \%)$ the responses to acetylcholine (ACh) were significantly greater but they gradually decreased during repeated use of the biosensor as a result of regular leaching of the enzyme from the bioselective element. Therefore, in further experiments, GA in concentration $0.4 \%$ was used since the responses to the substrate were quite high and no rapid decrease was observed during continuous operation.

The biosensor operation was also tested depending on the duration of the enzyme immobilization (when creating a bioselective element) (from 20 to $40 \mathrm{~min}$ ). During 20 min immobilization, the responses gradually decreased because of insufficient stability of the process. The responses obtained in the case of $40 \mathrm{~min}$ immobilization were smaller than in other cases, probably due to strong enzyme crosslinking. In further work, 25 min was taken as an optimal duration of enzyme immobilization because the responses were sufficiently large and stable.

The biosensor's analytical characteristics also depend on the composition of the bioselective membrane. This parameter significantly affects the biosensor sensitivity; therefore it was necessary to select an optimal ratio of components in the bioselective membrane. The next experiment was aimed at the selection of the optimal ratio of colloidal solution of gold nanoparticles (concentration of $38.6 \mu \mathrm{g} / \mathrm{ml}$ ) with the enzyme mixture (5\% AChE) during immobilization. As a result, a series of biosensors with different ratios of these two solutions $(5: 1,3: 1,2: 1,1: 1,1: 2,1: 3,1: 5)$ were obtained. The dependence of biosensor responses on the AChE to AuNPs ratio was checked, namely, the biosensor responses in the state of enzymatic saturation with the substrate $(2 \mathrm{mM}$ acetylcholine). As seen (Fig. 4), the optimal ratio of the solutions of enzyme and gold nanoparticles is 3:1.

To assess the effect of different concentrations of AuNPs on the biosensor characteristics, a group of biosensors was developed with different concentrations of AChE and AuNPs $(30 \mathrm{~nm})$ in their bioselective membranes. For each biosensor of this group, we measured several responses to ACh in the concentrations from the linear part of the calibration curves of the AChE biosensor (Fig. 5), which can be used to characterize the biosensor sensitivity. Analyzing the obtained results, it can be seen that the responses of biosensors with AuNPs in concentrations of $38.6 \mu \mathrm{g} / \mathrm{ml}$ and $19.3 \mu \mathrm{g} / \mathrm{ml}$ were practically the same as those of the biosensor with AuNPs in the concentration of only $9.65 \mu \mathrm{g} / \mathrm{ml}$.

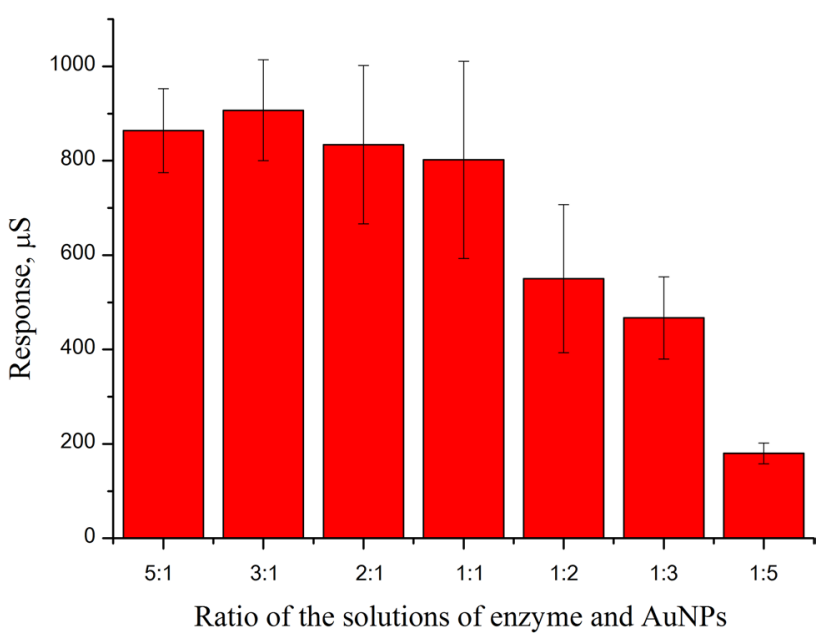

Fig. 4 Responses of AChE biosensors with different ratios of enzyme and gold nanoparticles in the bioselective element. Substrate (acetylcholine) concentration- $2 \mathrm{mM}$ 


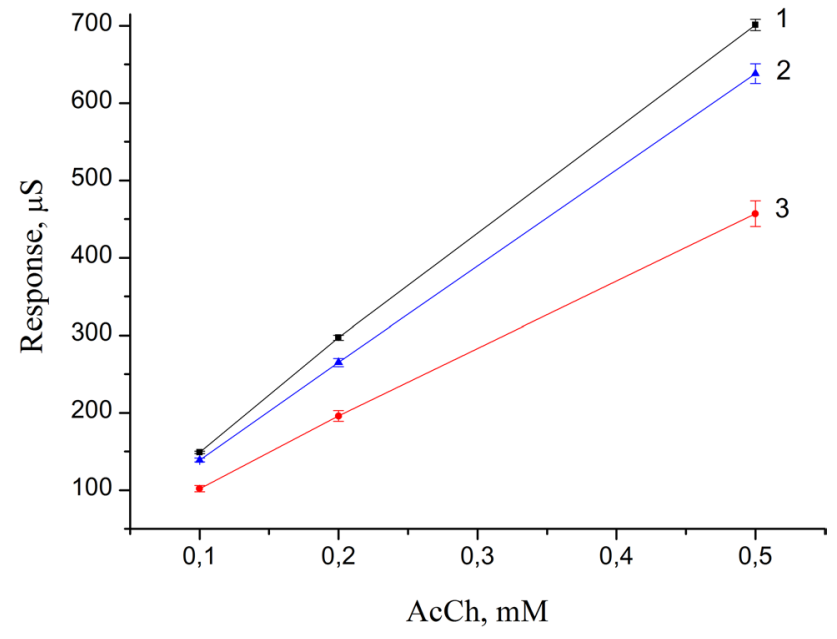

Fig. 5 Calibration curves of AChE biosensors based on of gold nanoparticles in different concentrations: $38.6 \mu \mathrm{g} / \mathrm{ml}(1), 19.3 \mu \mathrm{g} / \mathrm{ml}(2)$ and $9.65 \mu \mathrm{g} / \mathrm{ml}$

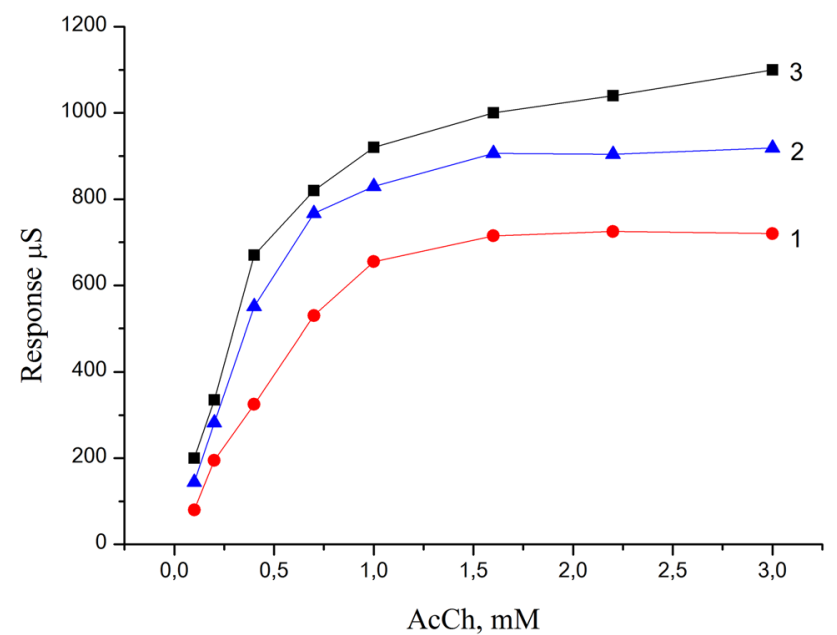

Fig. 6 Calibration curves of acetylcholinesterase- based biosensor without nanoparticles (curve 1), with gold nanoparticles of $20 \mathrm{~nm}$ (curve 2) and with gold nanoparticles of $30 \mathrm{~nm}$ (curve 3 )

To analyze the effect of gold nanoparticles on the immobilization of biological material and the functioning of biosensors, we compared the main characteristics of biosensors with and without gold nanoparticles, $20 \mathrm{~nm}$ and $30 \mathrm{~nm}$ in diameter. For adequate comparison, the same amount of enzyme was used in all methods of immobilization.

According to the results obtained, the calibration graphs were plotted for each type of biosensor (Fig. 6).

The obtained calibration curves show that the biosensors with $30 \mathrm{~nm}$ gold nanoparticles were characterized by the best sensitivity to AChE. The biosensor based on the traditional technique of immobilization, with no nanoparticles, had the best linear range of operation. Additionally to calibration curves, the parameters of real responses of the biosensor to different $\mathrm{ACh}$ concentrations were evaluated to analyze the noise, baseline drift and minimum limit of detection. For all variants of biosensors, the most important analytical characteristics were summarized in Table 1 .

Therefore, it was shown that it is quite possible and promising to create the biosensors by co-immobilization of the enzyme with AuNPs, and this variant of immobilization by the efficiency is not inferior to the common method of AChE immobilization in GA solution.

The aim of the next step of the investigation was to show whether the same AuNPs ( $30 \mathrm{~nm}$ ) can be used to immobilize other enzymes, which are frequently used in biosensoricsbutyrylcholinesterase (BuChE) and glucose oxidase (GOD). These enzymes catalyze the conversion of butyrylcholine (BuCh) (2) and glucose (3):

$$
\text { Butyrylcholine }+\mathrm{H}_{2} \mathrm{O} \rightarrow \text { Choline }+\mathrm{CH}_{3}\left(\mathrm{CH}_{2}\right)_{2} \mathrm{COO}^{-}+\mathrm{H}^{+}
$$

GOD

$\beta$ - D - glucose $+\mathrm{O}_{2} \rightarrow \mathrm{D}$ - gluconolactone $+\mathrm{H}_{2} \mathrm{O}_{2}$ $\Downarrow$

$\mathrm{D}$ - gluconic acid $+\mathrm{H}_{2} \mathrm{O} \rightleftharpoons$ acid residue $+\mathrm{H}^{+}$

The ions formed in these reactions change the solution conductivity, which can be registered by a conductometric transducer (Jaffrezic-Renault and Dzyadevych 2008; Soldatkin et al. 2008).

For immobilization, we used $30 \mathrm{~nm}$ AuNPs, which showed in the previous part of the work the best results for AChE biosensors. The obtained calibration curves of the biosensors based on co-immobilization of enzymes BuChE and GOD with AuNPs were compared with the calibration

\begin{tabular}{|c|c|c|c|c|c|}
\hline Type of immobilization & $\begin{array}{l}\text { Sensitivity } \\
(\mu \mathrm{S} / \mathrm{mM})\end{array}$ & $\begin{array}{l}\text { Minimum limit of } \\
\text { detection }(\mu \mathrm{M})\end{array}$ & $\begin{array}{l}\text { Linear range of opera- } \\
\text { tion, }(\mathrm{mM})\end{array}$ & $\operatorname{Drift}(\mu \mathrm{S} / \mathrm{min})$ & Noise $(\mu \mathrm{S})$ \\
\hline In a GA drop without AuNPs & 783 & 2.0 & to 0.7 & 12.3 & 5.2 \\
\hline In a GA drop with AuNPs $(30 \mathrm{~nm})$ & 1835 & 1.0 & to 0.4 & 12.1 & 6.1 \\
\hline In a GA drop with AuNPs $(20 \mathrm{~nm})$ & 1354 & 1.5 & to 0.4 & 15.3 & 6.8 \\
\hline
\end{tabular}

Table 1 Comparison of characteristics of biosensors based on different options of immobilization 

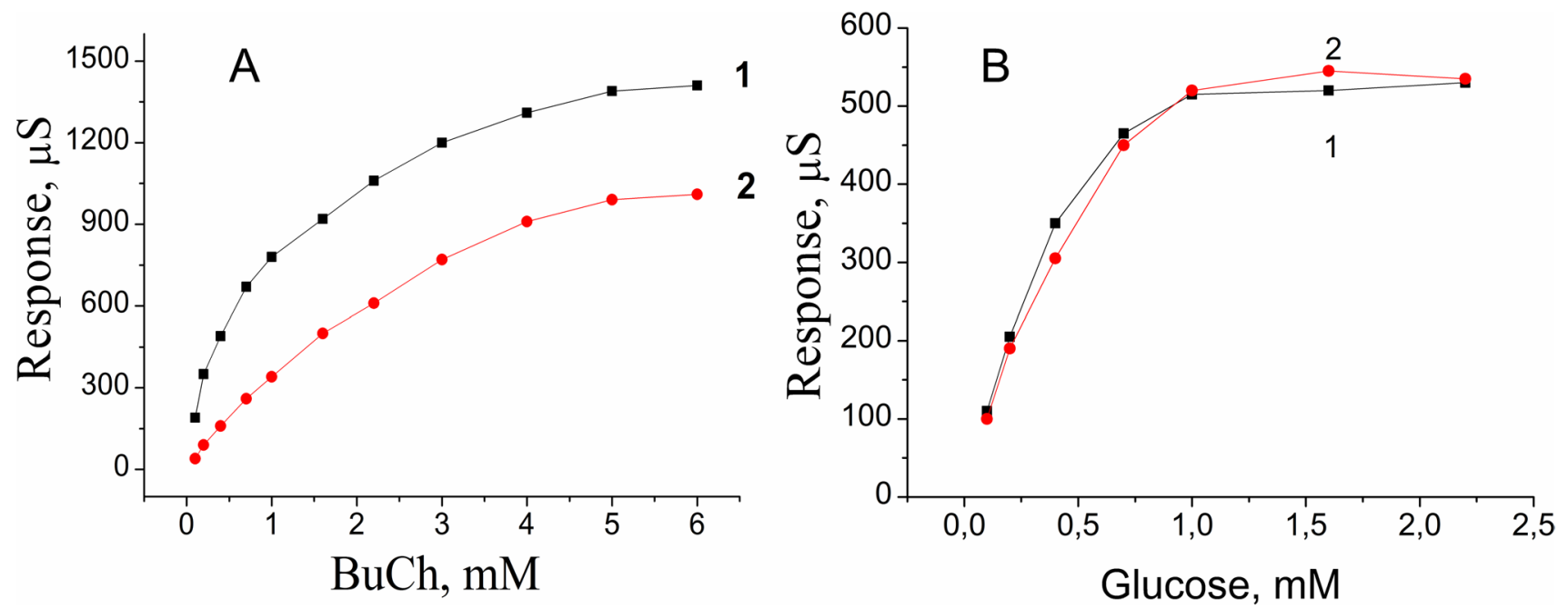

Fig. 7 Calibration curves of the biosensors based on butyrylcholinesterase (a) and glucose oxidase (b) without nanoparticles (1) and with $30 \mathrm{~nm}$ AuNPs (2)

curves of the biosensors based on traditional immobilization in glutaraldehyde solution (Fig. 7). It turned out that the use of AuNPs in the BuChE-based biosensor had a positive effect on its sensitivity to BuCh (Fig. 7a). The GOD-based biosensors with AuNPs were quite suitable for utilization, however, as can be seen from Fig. 7b, they had a slightly narrower linear range of operation, and their sensitivity to glucose was almost the same as that of the biosensors based on GOD only.

Another important characteristic of biosensors is the reproducibility of their performance. To investigate how the presence of AuNPs in the biosensor membrane affects this characteristic, we measured the responses of biosensors based on different enzymes (AChE, BuChE and GOD) with and without AuNPs to the corresponding substrates in the concentration of $1 \mathrm{mM}$ over one working day with 40-min intervals. Between measurements, all tested biosensors were kept in the working buffer solution at room temperature. For comparison, the mean-root-square error of measurements was calculated; the results are listed in Table 2. As can be seen, all biosensors based on different enzymes with/without AuNPs during quasi-continuous operation over one working day were characterized by high signal reproducibility. Thus, the addition of AuNPs to bioselective elements almost does not influence the biosensor stability.

An important characteristic of any biosensor is the reproducibility of its preparation (inter-reproducibility of responses). It is reflected in the standard deviation of responses of the biosensors, which are obtained using different variants of the enzyme immobilization on the surface of the same transducer. This parameter is especially important in the industrial production of large batches of biosensors whereas it is often neglected in the development of laboratory prototypes. Thus, when enzymes are immobilized in glutaraldehyde several times, there is a significant discrepancy in biosensor responses. It can be due to a human factor (since it is the researcher who deposits a layer of enzyme solution to form the sensitive membrane) as well as because of random changes in the conditions of immobilization. To prove that the addition of AuNPs to bioselective elements does not negatively affect the biosensor characteristics, we

Table 2 Comparison of biosensor characteristics at different methods of immobilization of enzymes with/without AuNPs

\begin{tabular}{|c|c|c|c|c|c|c|}
\hline \multirow[t]{2}{*}{ Characteristics } & \multicolumn{6}{|c|}{$\begin{array}{l}\text { Biosensors based on enzymes immobilized in GA solution } \\
\text { with/without AuNPs }\end{array}$} \\
\hline & $\overline{\mathrm{AChE}}$ & $\begin{array}{l}\text { AChE } \\
\text { with } \\
\text { AuNPs }\end{array}$ & $\mathrm{BuChE}$ & $\begin{array}{l}\text { BuChE } \\
\text { with } \\
\text { AuNPs }\end{array}$ & GOD & $\begin{array}{l}\text { GOD } \\
\text { with } \\
\text { AuNPs }\end{array}$ \\
\hline RSD of biosensor responses for different variants of enzyme immobilization, $\%$ & 19 & 18 & 22 & 21 & 15 & 17 \\
\hline RSD of biosensor responses during continuous operation $(n=15), \%$ & 1.1 & 1.0 & 3.2 & 3.4 & 2.2 & 2.3 \\
\hline Residual activity of the bioselective element after 7 -day dry storage at $+4^{\circ} \mathrm{C}, \%$ & 92.3 & 93.4 & 78.9 & 79.6 & 91.3 & 94.1 \\
\hline
\end{tabular}


evaluated the reproducibility of biosensors based on different enzymes with and without AuNPs.

The summarizing data of the mean-root-square deviation of biosensor responses for different variants of enzyme immobilization with/without AuNPs are given in Table 2. As expected, the immobilization of enzymes in the presence of AuNPs was not worse, and for AChE and BuChE even slightly better, which is one more advantage of this method of creating a bioselective element of the biosensor.

Next, a number of experiments were performed to study the storage stability of the biosensors based on different options of enzymes immobilization with/without AuNPs. The biosensors were stored dry at a temperature of $+4^{\circ} \mathrm{C}$. The activity of GOD- and AChE-based bioselective elements with AuNPs was stable for at least 7 days (loss of activity up to 7\%). During the same storage time, the biosensors based on enzymes only (with no nanoparticles) lost up to $9 \%$ of their activity. The situation was worse for the BuChE-based biosensors with and without AuNPs, in both cases they lost more than $20 \%$ of their activity during 7 days.

Thus, the investigation of the effect of adding AuNPs in the bioselective element of the biosensor demonstrated the prospects of this approach. The application of the proposed method of immobilization at least improved the sensitivity of AChE- and BuChE-based biosensors and did not negatively affect other characteristics.

\section{Conclusions}

We investigated the prospects of using gold nanoparticles for the modification of enzyme biosensors to improve their analytical characteristics. The conditions of co-immobilization of the enzyme with AuNPs were optimized. It was shown that the concentration of glutaraldehyde $0.4 \%$ and the duration of immobilization 25 min are optimal for the immobilization of AChE with AuNPs. When applying membranes on the transducer, the best ratio of the enzyme mixtures (5-10\%) and AuNPs (30 nm, $38.6 \mu \mathrm{g} / \mathrm{ml})$ was shown to be 3:1. The influence of AuNPs concentration and diameter on the biosensor sensitivity was studied.

Analytical characteristics of the enzyme-based biosensors with the addition of AuNPs were compared with characteristics of the biosensors based on enzyme only. It is shown that the responses reproducibility during continuous operation and the preparation stability of biosensors with nanoparticles are not worse than those of biosensors based on enzymes only (without nanoparticles). The storage stability of both variants of biosensors based on different enzymes was also compared. All biosensors based on the co-immobilization of enzymes with AuNPs were stored slightly better than the biosensors based on the same enzymes without AuNPs.
It has been proven that the addition of AuNPs to bioselective elements can improve the sensitivity and other parameters of biosensors, which is considered a positive result.

Acknowledgements The work was carried out thanks to financial support from the National Research Fund of Ukraine in the framework of the competition of projects for research and development "Support of research of leading and young scientists" (project 2020.02/0097, contract №03/02.2020) and NAS of Ukraine in the framework of the target research program of NAS of Ukraine "Smart" sensor devices of the new generation based on modern materials and technologies".

\section{Declarations}

Conflict of interest On behalf of all authors, the corresponding author states that there is no conflict of interest.

Open Access This article is licensed under a Creative Commons Attribution 4.0 International License, which permits use, sharing, adaptation, distribution and reproduction in any medium or format, as long as you give appropriate credit to the original author(s) and the source, provide a link to the Creative Commons licence, and indicate if changes were made. The images or other third party material in this article are included in the article's Creative Commons licence, unless indicated otherwise in a credit line to the material. If material is not included in the article's Creative Commons licence and your intended use is not permitted by statutory regulation or exceeds the permitted use, you will need to obtain permission directly from the copyright holder. To view a copy of this licence, visit http://creativecommons.org/licenses/by/4.0/.

\section{References}

Dzyadevych SV (2005) Conductometric enzyme biosensors: theory, technology, application. Biopolym Cell 21(2):91-106. https://doi. org/10.7124/bc.0006E1

Frens G (1973) Controlled nucleation for the regulation of the particle size in monodisperse gold suspensions. Nat Phys Sci 241:20-22. https://doi.org/10.1038/physci241020a0

Jaffrezic-Renault N, Dzyadevych SV (2008) Conductometric microbiosensors for environmental monitoring. Sensors 8:2569-2588. https://doi.org/10.3390/s8042569

Jia L, Zhou Y, Wu K, Feng Q, Wang Ch, He P (2019) Acetylcholinesterase modified AuNPs-MoS2-rGO/PI flexible film biosensor: towards efficient fabrication and application in paraoxon detection. Bioelectrochemistry 131:107392. https://doi.org/10.1016/j. bioelechem.2019.107392

Hondred JA, Breger JC, Garland NT, Oh E, Susumu K, Walper SA, Medintz IL, Claussen JC (2017) Enhanced enzymatic activity from phosphotriesterase trimer gold nanoparticle bioconjugates for pesticide detection. Analyst 142:3261-3271. https://doi.org/ 10.1039/C6AN02575G

Kerman K, Saito M, Tamiya E, Yamamura S, Takamura Y (2008) Nanomaterial-based electrochemical biosensors for medical applications. TrAC Trends Anal Chem 27:585-592. https://doi.org/10. 1016/j.trac.2008.05.004

Pavlov V, Xiao Y, Willner I (2005) Inhibition of the Acetycholine esterase-stimulated growth of Au nanoparticles: nanotechnology-based sensing of nerve gases. Nano Lett 5:649-653. https://doi.org/10. 1021/n1050054c

Ribeiro FWP, Barroso MF, Morais S, Viswanathan S, de Lima-Neto P, Correia AN, Oliveira MBPP, Delerue-Matos C (2014) Simple laccase-based biosensor for formetanate hydrochloride quantification 
in fruits. Bioelectrochemistry 95:7-14. https://doi.org/10.1016/j. bioelechem.2013.09.005

Soldatkin OO, Peshkova VM, Dzyadevych SV, Soldatkin AP, JaffrezicRenault N, El'skaya AV (2008) Novel sucrose three-enzyme conductometric biosensor. Mater Sci Eng, C 28:959-964. https://doi. org/10.1016/j.msec.2007.10.034

Turkevich J, Hillier J, Stevenson PC (1951) A study of the nucleation and growth processes in the synthesis of colloidal gold. Disc Farad Soc 11:55. https://doi.org/10.1039/DF9511100055

Vaghela C, Kulkarni M, Haram S, Aiyer R, Karve M (2018) A novel inhibition based biosensor using urease nanoconjugate entrapped biocomposite membrane for potentiometric glyphosate detection. Int J Biol Macromol 108:32-40. https://doi.org/10.1016/j.ijbio mac.2017.11.136

Valencia GA, de Oliveira Vercik LC, Vercik A (2014) A new conductometric biosensor based on horseradish peroxidase immobilized on chitosan and chitosan/gold nanoparticle films. J. Polym. Eng. 34(7):633-638. https://doi.org/10.1515/polyeng-2014-0072
Yang X, Feng M, Xia J, Zhang F, Wang Z (2020) An electrochemical biosensor based on AuNPs/Ti3C2 MXene three-dimensional nanocomposite for microRNA-155 detection by exonuclease IIIaided cascade target recycling. J Electroanal Chem 878:114669. https://doi.org/10.1016/j.jelechem.2020.114669

Zhou Y, Wang M, Yin H, Ai S (2017) Amperometric determination of the activity of protein kinase a using a glassy carbon electrode modified with IgG functionalized gold nanoparticles conjugated to horseradish peroxidase. Microchim Acta 184:3301-3308. https:// doi.org/10.1007/s00604-017-2341-x

Publisher's Note Springer Nature remains neutral with regard to jurisdictional claims in published maps and institutional affiliations. 